\title{
OPEN Prevalence of total hepatitis A antibody among 5 to 7 years old children and their mothers in Cambodia
}

\author{
Shintaro Nagashima ${ }^{1}$, Ko Ko ${ }^{1}$, Chikako Yamamoto ${ }^{1}$, E. Bunthen ${ }^{1,2}$, Serge Ouoba ${ }^{1,3}$, \\ Channarena Chuon ${ }^{1,4}$, Masayuki Ohisa ${ }^{1}$, Aya Sugiyama ${ }^{1}$, Tomoyuki Akita ${ }^{1}$, \\ Md. Shafiqul Hossain ${ }^{5}$, Vichit Ork ${ }^{6}$, Bunsoth $\mathrm{Mao}^{7}$ \& Junko Tanaka ${ }^{1 凶}$
}

This study determined the prevalence of total hepatitis A antibody (anti-HAV) among 5-7 years old children and their mothers in the whole Cambodia, using a nationwide study, and examined the differences between the two cohorts. A total of 4535 dried blood spot-driven (DBS) samples (2021 mothers and their 2514 children of 5-7 years old) and the concomitant 922 whole blood samples (subset of the whole participants) were collected using a multistage random sampling strategy throughout Cambodia in 2017. Total anti-HAV was detected using the chemiluminescence enzyme immunoassay method. Compared to gold standard whole blood samples, the sensitivity and specificity of DBS mediated anti-HAV detection were $94.8 \%$ and $98 \%$, respectively. Total anti-HAV prevalence among mothers was $91.2 \%(95 \% \mathrm{Cl}: 90.0-92.5 \%)$, and that of their children was $31.5 \%$ (95\% Cl: 29.7-33.3\%). In our study, the low prevalence of total anti-HAV among children indicates the country's improvement of safe water and food supply, hygiene and sanitation. If the hygiene and sanitation are consistently improved in Cambodia, the prevalence might be no longer increased when the children become adults.

Viral hepatitis A is caused by hepatitis virus A (HAV), a small, naked single-stranded positive RNA virus which can survive on hands and non-porous environments as well as various kinds of foods ${ }^{1}$. Therefore, the transmission route is fecal-oral, and sporadic forms of epidemic outbreaks were reported worldwide. There were also reports on HAV outbreaks among vulnerable groups of people, such as Men who have sex with Men (MSM) and people with intravenous drug use (PWIDs) ${ }^{2}$. Once infected, almost all individuals fully recover with lifelong immunity. But the outcome can be fatal, especially if the disease progresses rapidly to fulminant hepatitis.

According to World Health Organization (WHO), hepatitis A caused approximately 7134 deaths in 2016, which accounts for $0.5 \%$ of the mortality due to viral hepatitis ${ }^{3}$. The prevalence may vary in each continent or country, but it is closely associated with food and water safety, as well as personal hygiene and sanitation. A multistate outbreak of HAV in the United States in 2016 was reported and all the outbreaks were linked to food-born origin $^{4}$. The outbreak in developing countries had experienced much health burden than developed countries ${ }^{5,6}$.

In Cambodia, there were only a few reports on the prevalence of HAV last decade ${ }^{7-9}$. The increasing trend of HAV prevalence by age was observed, and almost $100 \%$ of Cambodian adults were positive for antibodies to hepatitis A virus (anti-HAV) Immunoglobulin G $(\operatorname{IgG})^{9}$. No more studies were conducted for HAV infection in Cambodia since 1998, so that the current disease burden is unexplored. Additionally, the Kingdom of Cambodia is now vehemently moving forwards and the economics, environment, and health care system are improving day by day ${ }^{10}$. Positive economic and societal changes create better sanitation, safe food and water supply, and proper hygiene, leading to a healthy lifestyle. Alongside the development of Cambodia, understanding the trend of infectious diseases is crucial for its specific prevention and control. We expected that anti-HAV prevalence in

\footnotetext{
${ }^{1}$ Department of Epidemiology, Infectious Disease Control and Prevention, Hiroshima University Graduate School of Biomedical and Health Sciences, 1-2-3, Kasumi, Minami-ku, Hiroshima 734-8551, Japan. ${ }^{2}$ Payment Certification Agency, Ministry of Health of Cambodia, Phnom Penh, Cambodia. ${ }^{3}$ Unité de Recherche Clinique de Nanoro (URCN), Nanoro, Burkina Faso. ${ }^{4}$ Faculty of Medicine, University of Puthisastra, Phnom Penh, Cambodia. ${ }^{5}$ Expanded Programme On Immunization, World Health Organization Country Office, Phnom Penh, Cambodia. ${ }^{6}$ National Immunization Programme, Ministry of Health, Phnom Penh, Cambodia. ${ }^{7}$ University of Health Sciences, Phnom Penh, Cambodia. ${ }^{\varpi}$ email: jun-tanaka@hiroshima-u.ac.jp
} 
Cambodia would decrease than before. Thus, this study determined the prevalence of total hepatitis A antibody (anti-HAV) among 5-7 years old children and their mothers in the whole Cambodia, using a nationwide study and examined the differences between the two cohorts.

\section{Methods}

This study is the continuum of our nationwide epidemiological study on the prevalence of hepatitis virus, including HAV, among 5-7 years old children and their mothers in Cambodia. Data collection was conducted in 2017, using a multistage stratified random sampling strategy ${ }^{11}$. The detailed study design procedure and sampling strategy were described in our previously published work ${ }^{11}$. In this study, we report the total anti-HAV prevalence among children and their mothers.

Subjects. This study included two main groups of subjects.

i. 5-7 years old children who were born between March 2010 and February 2012 and represented the new generation after the country's gross development

ii. Mothers of the above-mentioned children, who represented the generation before the country's gross development

Exclusion criteria included children who were not able to give blood because of underlying severe illness or hemophilia, and children whose caregivers did not provide consent for blood sampling.

Demographic data. Our study included a questionnaire survey designed to explore the immunization status of children, particularly hepatitis B, but the demographic data were also useful for HAV infection. Age, sex, socio-economic status, infectious disease status, and immunization status were extracted and employed to correlate total anti-HAV positivity.

Collection of blood samples. Two types of sampling techniques were used in this study.

i. Dried blood spot sampling technique using HemaSpot-HF (Spot on Science Inc., Austin, USA) was used to collect the blood samples from all participants by finger prick. Approximately $60 \mu \mathrm{l}(\mu \mathrm{l})$ of blood $(3$ drops) were collected into the HemaSpot-HF device and then kept with a desiccant (silica) at $-80^{\circ} \mathrm{C}$ until measurement.

ii. Three milliliters ( $\mathrm{ml}$ ) of whole blood samples using venipuncture were collected from randomly selected subgroups of participants (405 mothers and 517 children). The samples were centrifuged, and only the serum was stored at $-80^{\circ} \mathrm{C}$ until measurement.

Detection of total anti-HAV. Total anti-HAV was directly detected from all serum-derived and DBS samples. Measurement was done directly from the serum samples. But DBS driven samples were firstly eluted with an elution buffer at room temperature as previously described ${ }^{12}$. Then, $20 \mu$ l elute was mixed with $60 \mu$ of $7.5 \mathrm{w} / \mathrm{v} \%$ albumin D-PBS solution (Wako Pure Chemical Industries, Ltd, Osaka, Japan) before the detection of total anti-HAV.

Total anti-HAV was detected by chemiluminescence enzyme immunoassay method (CLEIA) using VITROS ECiQ Immunodiagnostic System (Ortho Clinical Diagnostics Inc., New Jersey, USA). The resultant C.O.I was interpreted to set the cut-off point for serum sample as follow;

(i) "positive" for total anti-HAV titer $<0.8$ C.O.I,

(ii) "borderline" for $1.0>$ total anti-HAV titer C.O.I $\geq 0.8$ and

(iii) "negative" for total anti-HAV titer $\geq 1.0$

Statistical analysis. To clarify the risk factors of total anti-HAV positivity among children, a multivariate logistic regression analysis using the stepwise selection method (both inclusion and exclusion criteria: $p<0.25$ ) was performed among 11 variables of the questionnaires, which included residing area, gender, place of birth, age, mother's HAV status, mother's age, mother's education, house roof, number of siblings, job and traveling time to the health center. For all analyses, $p<0.05$ was considered statistically significant. Using 922 pairs of serum and DBS samples from same participants, the sensitivity and the specificity of DBS-spotted total antiHAV detection were calculated against gold standard serum samples. The Receiver Operating Characteristic (ROC) curve was created by scatter plot. All the statistical tests were performed using JMP version 11 (SAS Institute, Cary, NC, USA).

Ethical consideration. Informed consent was obtained from the mother for her child and herself. If the mother was absent, the father or another caretaker was asked to provide consent for the child. Informed assent was obtained from all children in the study. All specimens and questionnaire data were de-identified, with reference only to a unique identifier. The study protocol was approved by the Cambodia National Ethics Committee for Human Research (392NECHR), the Ethics Review Committee for the WHO Western Pacific Region, and the Ethics Committee for Epidemiology of Hiroshima University (E-573). This activity was reviewed in accordance 
$\mathrm{N}=922$

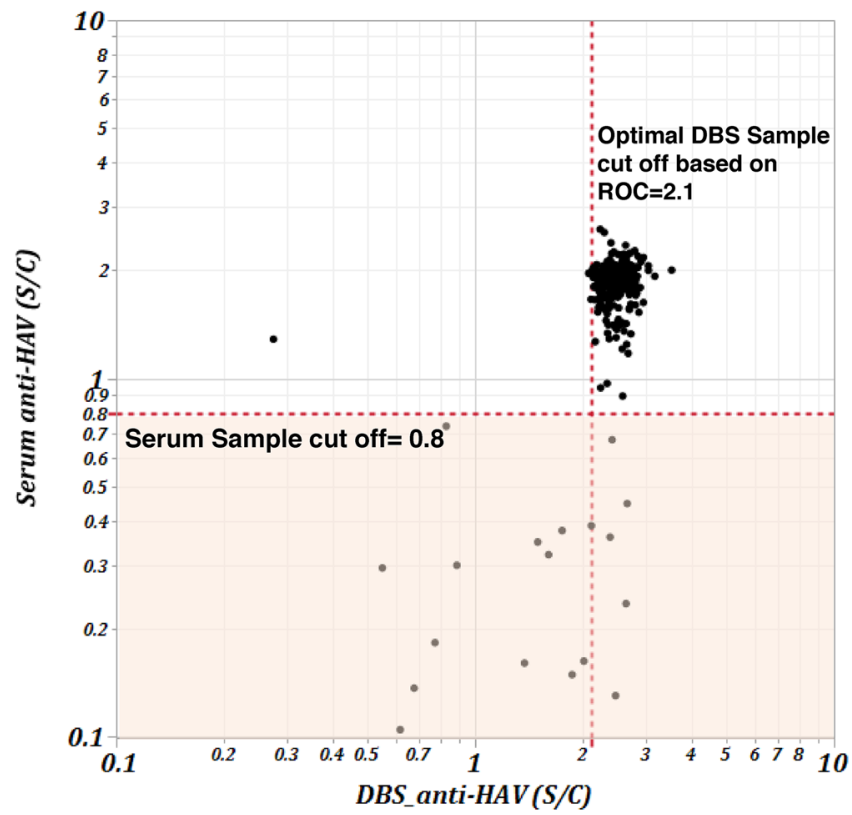

\section{Anti-HAV Total (CLEIA)}

Optimal DBS Sample cut off based on $R O C=2.1(S / C)$

Sensitivity $=94.8 \%(585 / 617)$

Specificity $=99.0 \%(302 / 305)$

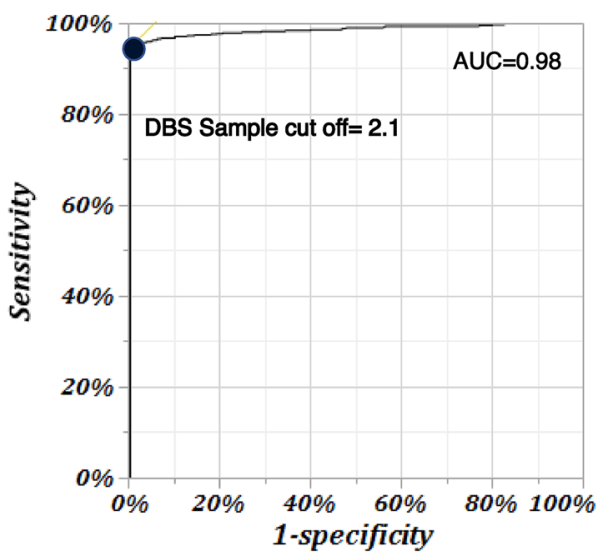

By ROC analysis, C.O.I, the sensitivity and specificity of DBS samples $(\mathrm{N}=922)$ were $2.1,94.8 \%$ and $99.0 \%$ respectively.

Figure 1. Scatter plot of Serum and DBS sample in Total-HAV Ab. This figure shows the agreement on the measure value of total anti-HAV between dried blood spot sample-driven samples and whole blood samples from 922 randomly selected participants in Cambodia. The scattered plot shows the cut-off value for the detection of total anti-HAV from DBS against the whole blood samples. The area under curve (AUC) was 0.98.

with the CDC human research protection procedures, and was determined to be human subject research, but CDC involvement did not constitute a direct engagement in human subject research.

\section{Results}

Subjects. A total of 4535 participants (2514 children and 2021 mothers) were included in the study. DBS samples were collected from each participant, and the serum samples were randomly additionally collected from 922 participants to evaluate the efficacy of DBS for total anti-HAV detection. The detailed characteristics of the enrolled children and their mothers were publicly stated in the previous report ${ }^{11}$. Of the enrolled children, 1270 (50.5\%) were male, and the number of 5, 6 and 7 years old children were $1234(49.1 \%), 1198(47.6 \%)$ and 82 (3.3\%), respectively. The mean age of mothers was $32.5 \pm 6.1$ years and reported a mean of 2.8 children (medium: 2) with a range of $1-12$ children.

Sensitivity and specificity of total anti-HAV from DBS samples against serum samples. The cut-off index of total anti-HAV titers from serum samples was defined at 0.8 . Using 922 serum samples, the sensitivity of DBS-driven samples was $94.8 \%$ (508/617), and the specificity was $99.0 \%(302 / 305)$. By mean of ROC analysis, the optimal cut-off index of total anti-HAV using DBS driven samples was set at 2.1 (AUC $=0.98)$. (Fig. 1).

Nationwide prevalence of total anti-HAV among children and their mothers. Using the DBS driven samples collected from all enrolled children and their mothers throughout the whole Cambodia, the total anti-HAV prevalence was 31.5\% (95\%CI: 29.7-33.3\%) in children and 91.2\% (95\%CI: 90.0-92.5\%) in mothers. The total anti-HAV prevalence varied by region and ranged from $5.6 \%$ to $56.9 \%$ among children and $77.6 \%$ to $100 \%$ among mothers (Table 1). The total anti-HAV prevalence of under $20 \%$ among children was found in Stung Treng, Preach Vihear and Otdar Meanchey provinces, followed by Koh Kong, Takeo, Svay Rieng and Banteay Meanchey provinces. The highest prevalence of total anti-HAV among children was found in Kampong Chhang followed by Kampong Speu, Preah Sihanouk, Kampong Thom and Kandal provinces. Meanwhile, the low prevalence among their mothers was found in Kracheh followed by Stung Treng and Preach Vihear provinces, all of which have prevalence under $80 \%$. The highest prevalence of total anti-HAV at $100 \%$ among their mothers was found in Kampot followed by prevalence of over 95\% in Siem Reap, Tboung Khmum, Kampong Speu, Battambang provinces. (Table 1, Fig. 2a,b). 


\begin{tabular}{|l|l|l|l|l|l|l|l|l|l|}
\hline \multirow{2}{*}{ No } & \multirow{9}{|c|}{ Children } & \multicolumn{3}{l|}{ Mothers } \\
\cline { 2 - 10 } & Province & No & $(+)$ & $P$ & $95 \%$ CI & No & $(+)$ & $P$ & $95 \%$ CI \\
\hline 1 & Banteay Meanchey & 144 & 28 & 19.4 & $13.0-25.9$ & 87 & 78 & 89.7 & $83.3-96.1$ \\
\hline 2 & Battambang & 180 & 49 & 27.2 & $20.7-33.7$ & 140 & 133 & 95.0 & $91.4-98.6$ \\
\hline 3 & Kampong Cham & 180 & 72 & 40.0 & $32.8-47.2$ & 154 & 138 & 89.6 & $84.8-94.4$ \\
\hline 4 & Kampong Chhnang & 72 & 41 & 56.9 & $45.5-68.4$ & 63 & 55 & 87.3 & $79.1-95.5$ \\
\hline 5 & Kampong Speu & 180 & 82 & 45.6 & $38.3-52.8$ & 151 & 144 & 95.4 & $92.0-98.7$ \\
\hline 6 & Kampong Thom & 144 & 63 & 43.8 & $35.6-51.9$ & 115 & 102 & 88.7 & $82.9-94.5$ \\
\hline 7 & Kampot & 72 & 15 & 20.8 & $11.5-30.2$ & 50 & 50 & 100.0 & $92.9-100.0$ \\
\hline 8 & Kandal & 179 & 76 & 42.5 & $35.2-49.7$ & 142 & 131 & 92.3 & $87.9-96.7$ \\
\hline 9 & Koh Kong & 72 & 10 & 13.9 & $5.9-21.9$ & 61 & 59 & 96.7 & $92.3-100$ \\
\hline 10 & Kracheh & 72 & 22 & 30.6 & $19.9-41.2$ & 67 & 52 & 77.6 & $67.6-87.6$ \\
\hline 11 & Otdar Meanchey & 36 & 3 & 8.3 & $0-17.4$ & 19 & 18 & 94.7 & $84.7-100$ \\
\hline 12 & Phnom Penh & 177 & 58 & 32.8 & $25.9-39.7$ & 122 & 111 & 91.0 & $85.9-96.1$ \\
\hline 13 & Preah Sihanouk & 36 & 16 & 44.4 & $28.2-60.7$ & 32 & 27 & 84.4 & $71.8-97.0$ \\
\hline 14 & Preah Vihear & 36 & 3 & 8.3 & $0-17.4$ & 33 & 26 & 78.8 & $64.8-92.7$ \\
\hline 15 & Prey Veng & 180 & 48 & 26.7 & $20.2-33.1$ & 141 & 128 & 90.8 & $86.0-95.6$ \\
\hline 16 & Pursat & 108 & 32 & 29.6 & $21.0-38.2$ & 103 & 89 & 86.4 & $79.8-93$ \\
\hline 17 & Ratanak Kiri & 36 & 10 & 27.8 & $13.1-42.4$ & 34 & 30 & 88.2 & $77.4-99.1$ \\
\hline 18 & Siem Reap & 180 & 70 & 38.9 & $31.8-46.0$ & 153 & 147 & 96.1 & $93.0-99.2$ \\
\hline 19 & Stung Treng & 36 & 2 & 5.6 & $0-13.0$ & 33 & 26 & 78.8 & $64.8-92.7$ \\
\hline 20 & Svay Rieng & 107 & 17 & 15.9 & $9.0-22.8$ & 92 & 83 & 90.2 & $84.1-96.3$ \\
\hline 21 & Takeo & 144 & 25 & 17.4 & $11.2-23.5$ & 112 & 105 & 93.8 & $89.3-98.2$ \\
\hline 22 & Tboung Khmum & 143 & 50 & 35.0 & $27.1-42.8$ & 117 & 112 & 95.7 & $92.1-99.4$ \\
\hline Total & & 2514 & 792 & 31.5 & $29.7-33.3$ & 2021 & 1844 & 91.2 & $90.0-92.5$ \\
\hline
\end{tabular}

Table 1. Area-specific prevalence of total anti-HAV among children and their mothers in Cambodia.

\section{a) Mother}

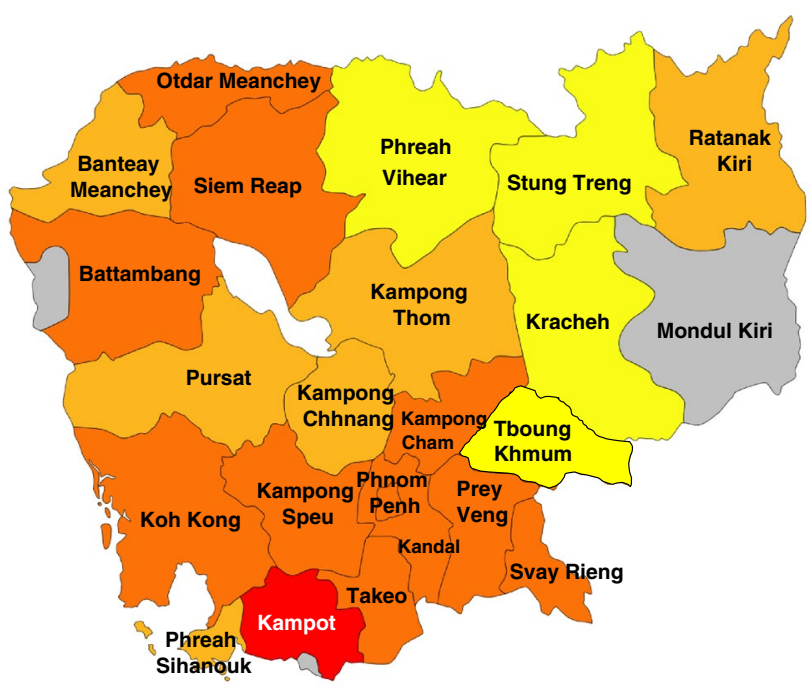

Total anti-HAV prevalence (\%)

100

90-99

80-89

No data b) Children

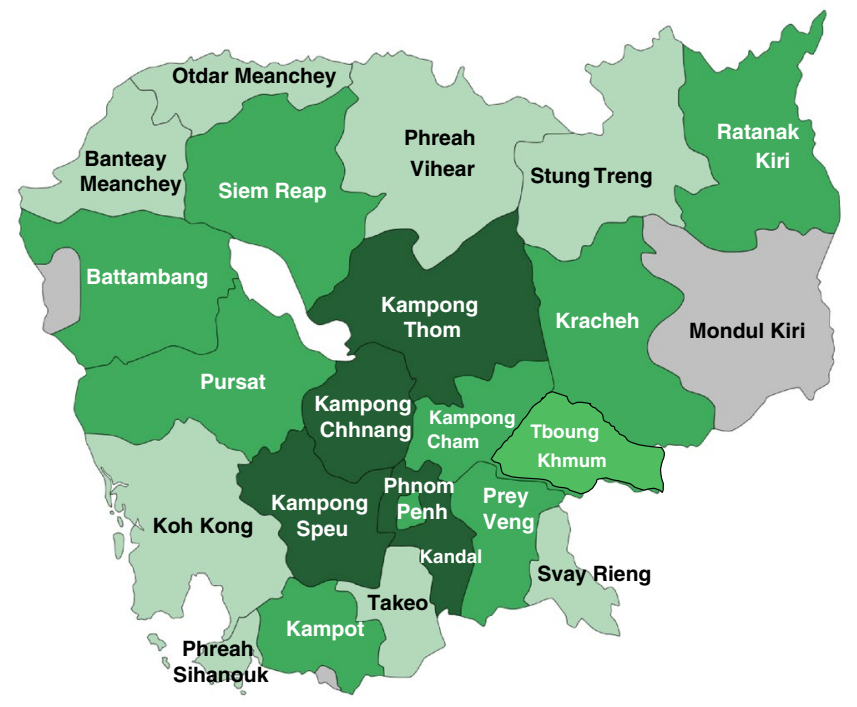

Total anti-HAV prevalence (\%)

40-59

20-39

0-19

No data

Figure 2. Population density and total anti-HAV prevalence of mother and their child in each province of Cambodia (a) represents the map showing total anti-HAV prevalence of mothers in each province of Cambodia in 2017 and similarly (b) shows for the children. The intensity of color in each map are changed by its value. 


\begin{tabular}{|c|c|c|c|c|c|c|c|}
\hline \multirow[b]{2}{*}{ Factors } & \multirow[b]{2}{*}{$\mathbf{N}$} & \multicolumn{3}{|c|}{ Univariate analysis } & \multicolumn{3}{|c|}{ Multivariate analysis } \\
\hline & & Anti-HAV (+) & $(\%)$ & $p$ value & AOR & $95 \% \mathrm{CI}$ & $p$ value \\
\hline \multicolumn{8}{|l|}{ Category } \\
\hline PP & 88 & 29 & 33.0 & $<0.0001$ & 1.29 & $0.80-2.08$ & 0.3014 \\
\hline Urban & 183 & 25 & 13.7 & & 0.41 & $0.26-0.64$ & 0.0001 \\
\hline Rural & 1748 & 577 & 33.1 & & 1.00 & Reference & \\
\hline \multicolumn{8}{|l|}{ Gender } \\
\hline Male & 1045 & 324 & 31.0 & 0.8031 & & & \\
\hline Female & 974 & 307 & 31.5 & & & & \\
\hline \multicolumn{8}{|l|}{ Place of birth } \\
\hline Public Hospital & 405 & 122 & 30.1 & 0.0002 & 1.00 & Reference & \\
\hline Health Center & 995 & 298 & 30.0 & & 0.88 & $0.68-1.15$ & 0.3581 \\
\hline Home & 414 & 163 & 39.4 & & 1.31 & $0.96-1.75$ & 0.0858 \\
\hline Other & 205 & 48 & 23.4 & & 0.82 & $0.55-1.22$ & 0.3225 \\
\hline \multicolumn{8}{|l|}{ Age } \\
\hline 5 years old & 980 & 288 & 29.4 & 0.0791 & 1.00 & Reference & \\
\hline 6-7 years old & 1039 & 343 & 33.0 & & 1.17 & $0.96-1.42$ & 0.1154 \\
\hline \multicolumn{8}{|l|}{ Mother HAV } \\
\hline Positive & 585 & 31.6 & 0.2331 & & & & \\
\hline Negative & 48 & 27.3 & & & & & \\
\hline \multicolumn{8}{|l|}{ Mother age } \\
\hline$<29$ years old & 695 & 223 & 32.1 & 0.6853 & 1.00 & Reference & \\
\hline $30-39$ years old & 1059 & 322 & 30.4 & & 0.82 & $0.66-1.03$ & 0.0909 \\
\hline$\geq 40$ years old & 265 & 86 & 32.5 & & 0.83 & $0.59-1.16$ & 0.2720 \\
\hline \multicolumn{8}{|l|}{ Mother education } \\
\hline No/primary & 1462 & 487 & 33.3 & 0.0040 & 1.00 & Reference & \\
\hline Junior High School & 435 & 116 & 26.7 & & 0.84 & $0.65-1.09$ & 0.1874 \\
\hline Senior HS/College & 122 & 28 & 23.0 & & 0.83 & $0.52-1.31$ & 0.4173 \\
\hline \multicolumn{8}{|l|}{ House roof } \\
\hline Tile & 501 & 158 & 31.5 & 0.2298 & 1.00 & Reference & \\
\hline Metal & 1271 & 401 & 31.6 & & 0.99 & $0.79-1.25$ & 0.9461 \\
\hline Cement & 38 & 6 & 15.8 & & 0.40 & $0.16-1.00$ & 0.0500 \\
\hline Other & 209 & 66 & 31.6 & & 0.93 & $0.65-1.34$ & 0.7154 \\
\hline \multicolumn{8}{|l|}{ Number of siblings } \\
\hline $0-2$ & 1049 & 303 & 28.9 & 0.0170 & 1.00 & Reference & \\
\hline$\geq 3$ & 970 & 328 & 33.8 & & 1.21 & $0.97-1.50$ & 0.0875 \\
\hline \multicolumn{8}{|l|}{ Father's Job } \\
\hline Fisherman & 70 & 38 & 54.3 & $<0.0001$ & 2.45 & $1.47-4.08$ & 0.0005 \\
\hline Other & 1949 & 593 & 30.4 & & 1.00 & Reference & \\
\hline \multicolumn{8}{|c|}{ Traveling time to health center } \\
\hline$\sim 15 \mathrm{~min}$ & 977 & 262 & 26.8 & $<0.0001$ & 1.00 & Reference & \\
\hline $15-29 \mathrm{~min}$ & 511 & 153 & 29.9 & & 1.17 & $0.92-1.49$ & 0.2114 \\
\hline $30-44 \mathrm{~min}$ & 353 & 134 & 38.0 & & 1.51 & $1.16-1.98$ & 0.0023 \\
\hline $45-59 \mathrm{~min}$ & 150 & 76 & 50.7 & & 2.41 & $1.68-3.47$ & $<0.0001$ \\
\hline Never & 28 & 6 & 21.4 & & 0.51 & $0.20-1.31$ & 0.1611 \\
\hline $\mathrm{N}=2019$ & $p<0.0001$ & & & & & & \\
\hline
\end{tabular}

Table 2. Univariate and multivariate analysis on positivity of total anti-HAV among children in Cambodia. Bold values are used to highlight the significant results having significant association.

Risk factors of total anti-HAV positivity among children. By multivariate logistic regression analysis, children from urban areas (Adjusted OR: 0.41, 95\%CI: $0.26-0.64, p=0.0001$ ) and the type of house roof (Cement, Adjusted OR: 0.40, 95\%CI: 0.16-1.00, $p=0.0500$ ) had a lower risk of HAV infection. The job of the household head (Fisherman, Adjusted OR: 2.45, 95\%CI: 1.47-4.08, $p=0.0005$ ) and the travelling time to the health center (30-44 min, Adjusted OR: 1.51, 95\%CI: 1.16-1.98, $p=0.0023$ \& 45-49 min, Adjusted OR: 2.41, 95\%CI: 1.68-3.47, $p<0.0001$ ) had a higher risk of HAV infection. (Table 2). 
Discussion. This study represents the first nationwide large-scale sero-epidemiological study on the prevalence of total anti-HAV among 5-7 years old children and their mothers in Cambodia, as of 2017. Detection of total anti-HAV indicates the past or present infection with HAV or vaccination against HAV. Although it cannot clarify them, it shows the previous exposure to HAV naturally or vaccination-mediated and is useful to examine the disease prevalence and its burden.

Considering the period of country's gross development, two cohorts were included in this study; 2021 mothers born before the country's gross development and 2514 children born after the country's gross development. The overall total anti-HAV prevalence among children was $31.5 \%$, and that among mothers was $91.2 \%$. We found a gross difference in total anti-HAV prevalence with a high prevalence profile in mothers and a low profile in children. Considering that mothers had long exposure time to HAV than their children and the impact of characteristics of two different cohorts, we suggested that this difference was due to age effect and cohort effect. However, our study reported the updated estimation on the prevalence of total anti-HAV among children and their mothers as representative of the whole country.

The report in 1993 stated that $27-97 \%$ of children and $100 \%$ of adults were infected with HAV in Takeo province ${ }^{9}$. Chhour YM et al. reported that $55 \%$ of viral hepatitis diagnosed among children admitted to the National Pediatric Hospital as of 1998 were due to $\mathrm{HAV}^{8}$. The prevalence of anti-HAV among children of that time reflects the mother cohort of our study when they were in childhood life. By our study, total anti-HAV prevalence among children ranged from 5.6 to $56.9 \%$ and that among mothers ranged from 77.6 to $100 \%$. After the country's improvement in safe water and food supply, hygiene and good sanitation, the prevalence decreased over two decades. However, a reduced anti-HAV prevalence exposes to future epidemics due to the lack of herd immunity among population ${ }^{13}$. This situation is now occurring in the developed countries like Japan. If the hygiene and sanitation are sustainably improved, or the current situation is kept the same in Cambodia, we suggest that the children might not have the same risky environment as their mothers, and the prevalence might be no longer increased when the children become adults. Therefore, it is essential to monitor changes in the prevalence and implement vaccination against hepatitis $\mathrm{A}$ if the situation changes significantly.

In our study, the within-country difference in total anti-HAV prevalence was found. Some provinces (Kampong Speu and Kandal) had a high prevalence of total anti-HAV in both mother and children cohort. Meanwhile, some provinces (Koh Kong, Kampot, Takeo, Prey Veng, Svay Rieng, Siem Reap, and Battanbbang) had an intermediate prevalence in the mother cohort but a high prevalence in the children cohort. This finding could suggest that safe food and water supply, hygiene and sanitation were not sufficiently improved in these regions. Moreover, internal migration should be considered, as positive cases may have moved to other areas. Interestingly, all provinces with high prevalence are located either in the seaside or along the Tonle Sap lake, where the majority are fishermen. The fishermen, dealing with the raw fishes everyday, and their lifestyle habitats superimpose the risk of HAV. In addition to the country's gross development, geographical preference with the majority of work, their tradition and lifestyle concomitantly related to the prevalence of HAV infection.

The above finding was supported by the subsequent multivariate analysis. By logistic regression, children living in urban areas and those with cement roof, a proxy indicator of socio-economic status, had the lowest HAV risks. But those whose fathers were fishermen and those living far from the health care center had the highest potential for HAV infection.

Another noteworthy finding of this study was that we used the DBS as the new sampling strategy instead of collecting whole blood samples from all participants. The validity and efficacy of DBS for detection of HBV sero-markers ${ }^{14}$ and also the usefulness of DBS for molecular analysis of $\mathrm{HBV}^{15}$ had been reported previously. This study examined the sensitivity and specificity of total anti-HAV detection using DBS-driven samples against gold standard serum samples and set the cutoff value for the DBS-driven samples. The reported sensitivity of $94.8 \%$ and the specificity of $99.0 \%$ were applicable for the detection of total anti-HAV using DBS-driven samples. This study elucidated the efficacy of DBS as a new sampling tool for large-scale epidemiological studies in resourcelimited countries with insufficient infrastructure, human resources, and technology.

There are some limitations in our study. Firstly, we could not identify the acute cases or immune due to vaccination, and HAV vaccination history was also unknown. Moreover, $94.8 \%$ sensitivity of the anti-HAV test used in this study may underestimate the true prevalence.

In conclusion, the low prevalence of total anti-HAV among children indicates the country's improvement of safe water and food supply, hygiene, and sanitation. If the hygiene and sanitation are consistently improved in Cambodia, the prevalence might be no longer increased when the children become adults. Otherwise, there is a potential outbreak in the future due to a lack of herd immunity. The public health sector should consider raising public awareness through hygiene promotion and preventive measures.

\section{Data availability}

All the data included in this study were fully described in the manuscript.

Received: 18 November 2020; Accepted: 5 February 2021

Published online: 26 February 2021

\section{References}

1. Sattar, S. A., Jason, T., Bidawid, S. \& Farber, J. Foodborne spread of hepatitis A: Recent studies on virus survival, transfer and inactivation. Can. J. Infect. Dis. 11, 159-163. https://doi.org/10.1155/2000/805156 (2000).

2. Ndumbi, P. et al. Hepatitis A outbreak disproportionately affecting men who have sex with men (MSM) in the European Union and European Economic Area, June 2016 to May 2017. Eurosurveillance 23, 1700641. https://doi.org/10.2807/1560-7917. ES.2018.23.33.1700641 (2018).

3. 3World_Health_Organization. Hepatitis virus A Fact Sheet. (2019). 
4. 4Centers_for_Diseases_Control_and_Prevention. Widespread outbreaks of hepatitis A across the United States. (Centers for Diseases Control and Prevention, United States, 2016).

5. David, A. M. Hepatitis A outbreaks-methods of intervention in South-East Asian countries. Int. J. Infect. Dis. 8, 201-209. https ://doi.org/10.1016/j.ijid.2003.09.005 (2004).

6. Franco, E., Meleleo, C., Serino, L., Sorbara, D. \& Zaratti, L. Hepatitis A: Epidemiology and prevention in developing countries. World J. Hepatol. 4, 68-73. https://doi.org/10.4254/wjh.v4.i3.68 (2012).

7. Poovorawan, Y., Chongsrisawat, V., Praianantathavorn, K. \& Theamboonlers, A. High seroprevalence of hepatitis A virus among migrant workers from Myanmar, Cambodia and Laos who are living in Thailand. Ann. Trop. Med. Parasitol. 103, 361-363. https ://doi.org/10.1179/136485909x435085 (2009).

8. Chhour, Y. M. et al. Hospital-based diagnosis of hemorrhagic fever, encephalitis, and hepatitis in Cambodian children. Emerg. Infect. Dis. 8, 485-489. https://doi.org/10.3201/eid0805.010236 (2002).

9. 9Thüring EG, J.-J. H., Sareth H, Sokhan U, Reth C, Grob P. Prevalence of markers of hepatitis viruses A, B, C and of HIV in healthy individuals and patients of a Cambodian province. Southeast Asian J. Trop. Med. Public. Health 24(2), 11 (1993).

10. Nationa_Institute_of_Statistics_Cambodia. Cambodia Socio-economic Survey 2017. (National Institute of Statistics, Cambodia, Phnom Penh, Cambodia, 2017).

11. Ork, V. et al. Hepatitis B surface antigen seroprevalence among pre- and post-vaccine cohorts in Cambodia, 2017. Vaccine 37, 5059-5066. https://doi.org/10.1016/j.vaccine.2019.06.073 (2019).

12. Lingani, M. et al. The changing epidemiology of hepatitis B and C infections in Nanoro, rural Burkina Faso: a random sampling survey. BMC Infect. Dis. 20, 46. https://doi.org/10.1186/s12879-019-4731-7 (2020).

13. Yamamoto, C. et al. Very low prevalence of anti-HAV in Japan: high potential for future outbreak. Sci. Rep. 9, 1493. https://doi. org/10.1038/s41598-018-37349-1 (2019).

14. Yamamoto, C. et al. Evaluation of the efficiency of dried blood spot-based measurement of hepatitis B and hepatitis $C$ virus seromarkers. Sci. Rep. 10, 3857. https://doi.org/10.1038/s41598-020-60703-1 (2020).

15. Ko, K. et al. Existence of hepatitis B virus surface protein mutations and other variants: demand for hepatitis B infection control in Cambodia. BMC Infect. Dis. 20, 305. https://doi.org/10.1186/s12879-020-05025-3 (2020).

\section{Acknowledgements}

The authors are grateful to the following collaborating researchers and private donors: Dr. Shunji Mishiro for his valuable help via the AAOHELP (Asia-Africa-Oceanea Hepatitis Expert Linkage Promotion) project of viral Hepatitis Research Foundation of Japan; Dr. Keiko Katayama and Dr. Tomoki Sato for participation in this survey; Professor Vonthanak Saphonn, Rector of the University of Health Sciences, Cambodia, for the cooperation in this survey; and Dr. Terumi Kaishima, Dr. Toshiko Fujii and Dr. Ayako Tabuchi for their generous donations for this survey.

\section{Author contributions}

Study concept and design: J.T., V.O. and M.S.H.; Conducting the study and training of field staffs: J.T., V.O., M.S.H., S.N., C.Y., C.C., T.A., B.M. and K.K.; Laboratory experiments: S.N., C.C. and K.K.; Data analysis: S.N., T.A., M.O., A.S., K.K., E.B. and O.S.; Data Interpretation: J.T., S.N., T.A. and A.S.; Manuscript development: S.N., K.K., E.B. and O.S.; Critical revision for important intellectual content: J.T., V.O. and M.S.H. All authors have read and approved the final version of manuscript.

\section{Funding}

This study was financially supported by, Hiroshima University, Department of Epidemiology, Infectious Disease Control and Prevention, Japan. Project Research Center for epidemiology and prevention of viral hepatitis and hepatocellular carcinoma, Hiroshima University, Japan (Director: Prof. Junko Tanaka). World Health Organization: The Expanded Programme on Immunization (EPI). Viral Hepatitis Research Foundation of Japan (AAOHELP: Asia-Afria-Oceanea Hepatitis Experts Linkage Promotion). National Center for Global Health and Medicine: NCGM (Contract Number: 29-2). The funder has no role in the study design, data collection, data analysis, data interpretation or writing of the report.

\section{Competing interests}

The authors declare no competing interests.

\section{Additional information}

Correspondence and requests for materials should be addressed to J.T.

Reprints and permissions information is available at www.nature.com/reprints.

Publisher's note Springer Nature remains neutral with regard to jurisdictional claims in published maps and institutional affiliations.

Open Access This article is licensed under a Creative Commons Attribution 4.0 International License, which permits use, sharing, adaptation, distribution and reproduction in any medium or format, as long as you give appropriate credit to the original author(s) and the source, provide a link to the Creative Commons licence, and indicate if changes were made. The images or other third party material in this article are included in the article's Creative Commons licence, unless indicated otherwise in a credit line to the material. If material is not included in the article's Creative Commons licence and your intended use is not permitted by statutory regulation or exceeds the permitted use, you will need to obtain permission directly from the copyright holder. To view a copy of this licence, visit http://creativecommons.org/licenses/by/4.0/.

(C) The Author(s) 2021 